\title{
Environmental regulatory oversight: transitioning from an operational to rehabilitation framework
}

\author{
JP Miller Department of Environment and Energy, Australia
}

\begin{abstract}
The primary objective of the Supervising Scientist is to protect the environment of the Alligator Rivers Region in the Northern Territory from the potential impacts of uranium mining activities, including uranium extraction and processing operations at the Ranger uranium mine (Ranger). The Supervising Scientist role was established in 1978 under the Environment Protection (Alligator Rivers Region) Act 1978. Operations at Ranger commenced in 1980, mining ceased in 2012, and stockpiled ore will continue to be processed until 2021. All rehabilitation works must be completed by 2026.

Environmental protection is assured through the Supervising Scientist's regulatory oversight program, which includes the assessment of mining and rehabilitation plans, reports and proposals, and a program of mine site inspections and environmental audits. The Supervising Scientist uses a risk-based approach to conduct impact assessment and site-specific research and monitoring to inform regulatory decision-making. This regulatory oversight role has been tailored to the nature and transitional status of Ranger from an operational to rehabilitating site.

This case study provides an overview of the Supervising Scientist's role in the regulatory oversight of Ranger. It looks at recent initiatives and refinements in oversight activities designed to ensure the regulatory system continues to assure the protection of the Alligator Rivers Region.
\end{abstract}

Keywords: consultation, environmental assessment, regulation, rehabilitation, supervision

\section{Introduction}

\subsection{Purpose}

This paper presents a case study of the Supervising Scientist's role in regulatory oversight of the Ranger mine as activities on this site move from a primarily operational to a large-scale rehabilitation focus. Changes in the Supervising Scientist's approach to supervisory activities and new initiatives in stakeholder consultation are discussed. This case study may be useful for other organisations with regulatory oversight responsibilities, to provide ideas on opportunities and initiatives to transitions their activities from an operational to rehabilitation focus.

\subsection{Uranium in the Alligator Rivers Region}

The Alligator Rivers Region (ARR) is located $220 \mathrm{~km}$ east of Darwin and encompasses an area of approximately $28,000 \mathrm{~km}$ (Figure 1). The ARR extends into western Arnhem Land and includes the catchments of the West Alligator, South Alligator, and East Alligator rivers. The dual World Heritage listed Kakadu National Park lies entirely within the ARR, as do the Ranger, Jabiluka, Nabarlek, and Koongarra uranium deposits.

Ranger is currently the only operational uranium mine in the ARR. The development of Jabiluka ceased in 1999 and the site remains under long-term care and maintenance. Operations at Nabarlek ceased in 1988 and the site has been substantially rehabilitated. There are also a number of former uranium mine sites in the South Alligator River Valley, in the southern section of Kakadu National Park that operated during the 1950 s and 1960s. The Australian Government funded the rehabilitation of these sites, which was completed in 2009. 


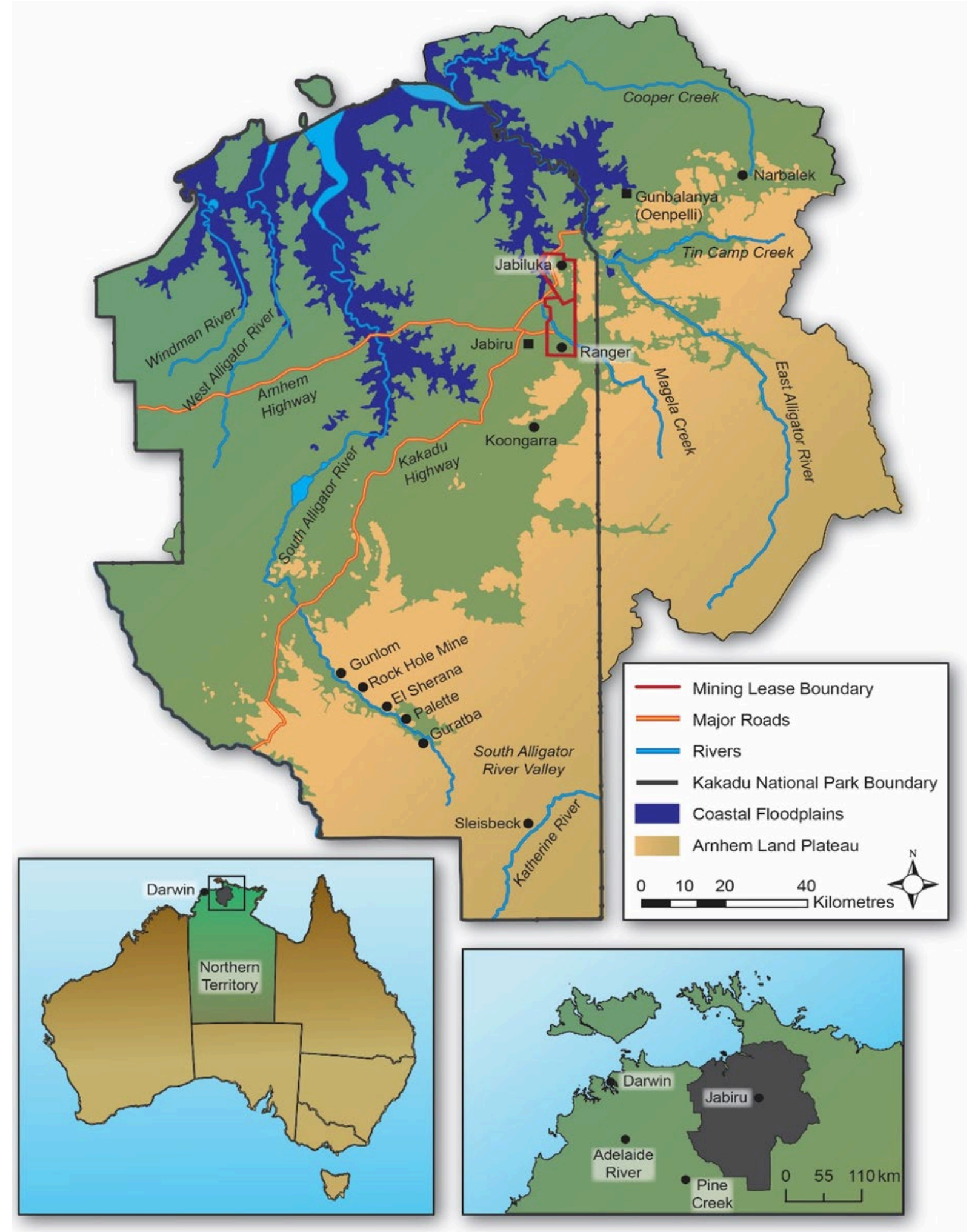

\section{Figure 1 Alligator Rivers Region}

\subsection{Ranger mine}

Ranger is located $8 \mathrm{~km}$ east of the township of Jabiru. The mine lies within the $78 \mathrm{~km}^{2}$ Ranger Project Area and is within the catchment of Magela Creek, a tributary of the East Alligator river.

Ranger is an open cut mine that has been producing uranium oxide via acid leach extraction since 1981. In accordance with current regulatory approvals, mining at Ranger ceased in 2012 and stockpiled ore will 
continue to be processed until 2021. Rehabilitation planning for Ranger has been underway for several years, with the mine operator publicly releasing a Ranger Mine Closure Plan in 2018 (Energy Resources of Australia Ltd 2018). All rehabilitation works must be complete by 2026 in accordance with the authority to mine uranium discussed in Section 1.4. Figure 2 provides an indicative schedule for the main rehabilitation activities that will be undertaken at Ranger to achieve compliance with the authority time frame requirements.

\begin{tabular}{|c|c|c|c|c|c|c|c|c|c|c|c|c|c|}
\hline \multirow[b]{2}{*}{ Aspect/Activity } & \multicolumn{13}{|c|}{ Timeline } \\
\hline & $\underset{\sim}{\stackrel{\sim}{\sim}}$ & $\stackrel{n}{\circ}$ & $\begin{array}{l}0 \\
\stackrel{-1}{N} \\
\end{array}$ & స్- & $\stackrel{\infty}{\stackrel{\infty}{0}}$ & 옹 & 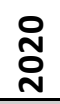 & స્. & స్ & $\stackrel{\text { N }}{\text { Dे }}$ & ্ָ & 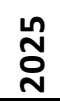 & ָั \\
\hline \multicolumn{14}{|l|}{ Pit 1 closure } \\
\hline \multicolumn{14}{|l|}{ Pit 3 closure } \\
\hline \multicolumn{14}{|l|}{ Tailings management } \\
\hline \multicolumn{14}{|l|}{ Brine management } \\
\hline \multicolumn{14}{|c|}{ Contaminated ites management } \\
\hline \multicolumn{14}{|l|}{ Processing plant closure } \\
\hline \multicolumn{14}{|l|}{ Water storage } \\
\hline \multicolumn{14}{|l|}{ Water treatment } \\
\hline All of site & & & & & & & & & & & & & \\
\hline
\end{tabular}

Figure 2 Ranger rehabilitation activities and schedule (Energy Resources of Australia Ltd 2018). ${ }^{1}$ All of site refers to rehabilitation activities such as final landform development and revegetation

\subsection{The Ranger mine regulatory framework}

The authority to mine uranium at Ranger is issued under Section 41 of the Atomic Energy Act 1953 (Commonwealth of Australia 1953), which is administered by the Commonwealth Minister for Resources and Northern Australia. Under the current authority, mining and milling activities at Ranger must cease on (or by) 8 January 2021, and rehabilitation works must be completed on (or by) 8 January 2026. No further authority can be issued without legislative amendment.

The authority also provides the Commonwealth's current environmental protection conditions, which are set out in the Environmental Requirements of the Commonwealth of Australia for the Operation of Ranger Uranium Mine (the Environmental Requirements) (Department of the Environment and Energy 1999). The Environmental Requirements outline key objectives and environmental standards for mining operations and rehabilitation. Under agreement, regulatory power over uranium mining in the Northern Territory is delegated to the Northern Territory government and given effect under the Mining Management Act 2001 (Government of the Northern Territory 2001).

The primary rehabilitation objective for Ranger, as set out in the Environmental Requirements, is to rehabilitate the site to a standard that, in the opinion of the Commonwealth Minister for Resources and Northern Australia, with the advice of the Supervising Scientist, enables it to be incorporated into the surrounding World Heritage listed Kakadu National Park. The Supervising Scientist provides advice to both the Commonwealth Minister for Resources and Northern Australia and the Northern Territory Minister for Primary Industry and Resources.

\section{Supervising Scientist Branch regulatory oversight functions}

The position of the Supervising Scientist was established under the Environment Protection (Alligator Rivers Region) Act 1978 (Commonwealth of Australia 1978) in response to a recommendation of the Ranger Uranium Environmental Inquiry final report (Commonwealth of Australia 1977) in May 1977. The Supervising 
Scientist Branch (SSB) supporting the Supervising Scientist has four key functions with respect to mining activities in the ARR: research, supervision, monitoring, and public assurance and advice.

The supervision activities are generally undertaken collaboratively with other stakeholder organisations with responsibilities or an interest in the rehabilitation of Ranger. The primary stakeholder group consists of representatives from SSB, DPIR, the Commonwealth Department of Industry Innovation and Science, the Northern Land Council (NLC), and Gundjeihmi Aboriginal Corporation (GAC) who represent the local Mirarr people. The involvement of traditional owner representative groups, such as the NLC and GAC, is considered essential in this collaborative approach to oversight to ensure cultural closure criteria are considered in all supervisory activities.

The SSB's oversight functions include the assessment of mining and rehabilitation plans, reports and proposals made by the mine operator under the Mining Management Act 2001. Through this assessment process, SSB can ensure that the operator's activities remain in compliance with the relevant Environmental Requirements.

The SSB also oversees a program of routine mine site inspections and environmental audits in conjunction with the primary stakeholder group. These activities allow stakeholders to review the mine operator's environmental performance and includes assessment of environmental incidents and associated investigations, ensuring the adequacy of systems in place to manage critical onsite risks.

As part of the regulatory oversight activities, stakeholder forums have also been established. The Alligator Rivers Region Advisory Committee provides a forum for community consultation on uranium mining activities in the region. This committee comprises representatives of government and regulatory bodies, representatives of traditional owners, public interest groups, and companies involved in uranium mining activities in the ARR. A Minesite Technical Committee (MTC) has also been established for Ranger, which provides a regular forum for the mine operator to discuss environmental management and regulatory issues with regulators and other primary stakeholders.

\section{Transitioning of operational oversight functions to a rehabilitation focus}

\section{1 $\quad$ Auditing}

Historically, stakeholder audits of Ranger have focused on the assessment of operational compliance to a specific statutory environmental management plan such as the water management plan, radiation management plan, or the mining management plan required under the Mining Management Act 2001. Selection of the audit scope would be based upon the level of risk associated with the activities described within the plan in consideration of trends in notified incidents and events. Typically, criteria were developed by first extracting commitments from the plan. Compliance to each criterion was evaluated through traditional auditing techniques such as interviews, onsite document review, and targeted inspections. A ranking was then applied to each commitment based upon the traditional grading description shown in Table 1. 
Table 1 Historical grading system with modified status examples

\begin{tabular}{|c|c|c|}
\hline Grading & Traditional grading description & Modified grading description \\
\hline $\begin{array}{l}\text { Category } 1 \\
\text { non- } \\
\text { conformance }\end{array}$ & $\begin{array}{l}\text { An identified activity is not in compliance } \\
\text { with the Authorisation, approval } \\
\text { document or applicable legislation and } \\
\text { could result in a high risk or is a persistent } \\
\text { Category } 2 \text { non-conformance. }\end{array}$ & $\begin{array}{l}\text { Activities, processes and systems evaluated } \\
\text { are not adequate, appropriate, or effective } \\
\text { to provide reasonable assurance that } \\
\text { rehabilitation objectives and timelines will } \\
\text { be met. }\end{array}$ \\
\hline $\begin{array}{l}\text { Category } 2 \\
\text { non- } \\
\text { conformance }\end{array}$ & $\begin{array}{l}\text { An isolated lapse of control or an } \\
\text { identified activity that is not in } \\
\text { compliance with the Authorisation, } \\
\text { approval document or applicable } \\
\text { legislation that could result in a low or } \\
\text { moderate risk. }\end{array}$ & $\begin{array}{l}\text { Numerous specific weaknesses were } \\
\text { noted. Activities, processes and systems } \\
\text { evaluated are unlikely to be adequate, } \\
\text { appropriate, or effective to provide } \\
\text { reasonable assurance that rehabilitation } \\
\text { objectives and timelines will be met. }\end{array}$ \\
\hline Conditional & $\begin{array}{l}\text { Action to meet the commitment has } \\
\text { commenced but is yet to be completed. }\end{array}$ & $\begin{array}{l}\text { A few specific weaknesses were noted. } \\
\text { Activities, processes and systems evaluated } \\
\text { are generally adequate, appropriate, and } \\
\text { effective to provide reasonable assurance } \\
\text { that rehabilitation objectives and timelines } \\
\text { will be met. }\end{array}$ \\
\hline Acceptable & The commitment has been met. & $\begin{array}{l}\text { Activities, processes and systems evaluated } \\
\text { are adequate, appropriate, and effective to } \\
\text { provide reasonable assurance that } \\
\text { rehabilitation objectives and timelines will } \\
\text { be met. }\end{array}$ \\
\hline Not verified & $\begin{array}{l}\text { Refers to items where compliance is not } \\
\text { able to be been assessed. This may also } \\
\text { include items that have been identified } \\
\text { during planning but have yet to } \\
\text { commence. }\end{array}$ & $\begin{array}{l}\text { Activities, processes and systems were not } \\
\text { unable to be evaluated. }\end{array}$ \\
\hline Observation & $\begin{array}{l}\text { An area that has notably improved or has } \\
\text { the potential to be improved or is outside } \\
\text { the scope of the audit but is notable. }\end{array}$ & $\begin{array}{l}\text { Notable activities, processes and systems } \\
\text { that are out of scope. }\end{array}$ \\
\hline
\end{tabular}

Major progressive rehabilitation activities at Ranger have been underway for several years involving several large, interdependent, and technically-complex rehabilitation projects. These included the transfer of processing tailings by dredging from the tailings storage facility to Pit 3, the backfill of Pit 1 with waste rock to facilitate tailings consolidation, and commissioning of a large-scale water treatment facility for treatment of contaminated process water. Stakeholders recognised that the systems by which the mine operator manages and monitors these activities were critical to ensure rehabilitation success and closure timeframes being met and that the ongoing protection of the environment was assured. Stakeholders needed confidence that the mine operator had the appropriate resources and management systems in place to monitor and manage these activities and to identify any emerging issues that may impact on the achievement of rehabilitation and closure objectives.

These major site rehabilitation activities necessitated a change in approach to the audits undertaken onsite. Rather than having commitments extracted from relevant management plans and site procedures, the audit in 2017 was based upon the mine operator demonstrating that they had embedded effective operational monitoring and management systems for the major rehabilitation works occurring onsite. The audit criteria were developed using high-level guiding questions, targeting specific environmental concerns for each 
rehabilitation activity. Examples of possible evidence sources to address the high-level questions were put forward by the audit team, however, the mine operator was encouraged to propose further relevant information that may have helped address each of the questions.

The guiding principle for the audit team was to drill down on the information provided until satisfied that the systems and resources in place were commensurate with the potential environmental and scheduling risks. Where there were gaps identified in this assessment, appropriate comments and grading were applied against the audit questions. This approach ensures that the audits help identify matters or emerging issues that may impact on the proposed rehabilitation schedule and closure of the site by 2026.

As this type of auditing was not designed to assess strict compliance, adjustments to the audit grading system were made. While the traditional rankings were used for each question, these rankings were assigned based upon the status of management strategies in place, in consideration of potential consequences to the environment and/or rehabilitation and closure timeframes. These modified grading descriptions are shown in Table 1.

An important aspect of this approach was the feedback provided to the mine operator through the audit findings. Gaps identified in management systems were explained, including the scope of information assessed and the rationale for the conclusions drawn. As this was not a strict compliance audit, there was more scope to elaborate on concerns raised and recommend possible pathways for resolution for the mine operator's consideration. There were also clear advantages to this approach for the stakeholders undertaking the audit. By focusing on the systems through an audit framework, stakeholder awareness and knowledge of the mine operator's management strategies for each rehabilitation activity was improved. This provided a higher level of assurance that environmental risks were being effectively managed, and the knowledge obtained from the audit could be carried forward to inform other supervisory activities such as inspections, stakeholder forum discussions, and subsequent assessment activities.

Following the success of this initial audit, the auditing approach described above has been applied to other environmental management aspects at Ranger, including groundwater management and monitoring, tailings deposition strategies, and surface water monitoring. Stakeholders recognised that there was still a need to monitor compliance with approved environmental management plans and other statutory obligations. Rather than assessing compliance through dedicated audits as had previously occurred, the inspection program (discussed in Section 3.2) was amended to include additional ongoing statutory compliance monitoring activities.

\subsection{Routine inspections}

Routine inspections usually involve representatives from SSB, DPIR, and NLC, and are undertaken at Ranger on a monthly basis. Previously, the focus and timetable were determined by a broad consideration of operational site activities and current topical matters including assessment of reported environmental incidents and statutory documents being assessed by stakeholders at the time of inspection.

Towards the end of 2017, an annual inspection program was developed for the coming year in consultation with the mine operator and other stakeholders. Each month was allocated an environmental theme, which considered what rehabilitation activities were likely to occur in a given month. Stakeholder visibility on the rehabilitation schedule was improved through the consultative forums discussed in Section 3.4 where there was increased focus on rehabilitation requirements such as statutory approvals and onsite execution strategies. By establishing an annual inspection program, the mine operator and stakeholders could ensure that appropriate staff, contractors, and other resources are available for the specific inspection themes.

In choosing the most appropriate times to undertake inspections consideration is given to the rehabilitation schedule including, construction, approval, and operational timeframes. Proposed rehabilitation locations may be inspected prior to commencement to inform current assessment and approval activities or to provide context for discussions at consultative forums. Where possible, follow-up inspections are undertaken while 
the rehabilitation activities are being undertaken to ensure activities are consistent with any approval conditions.

\subsection{Assessments of proposed rehabilitation activities}

The SSB assesses various documents submitted by the mine operator in accordance with the Environmental Requirements and the Ranger Authorisation, and provides advice to the regulators, the operator and key stakeholders. This advice traditionally has been focused on operational activities and routine submissions of statutory reports and plans.

Through the public release of the Ranger Mine Closure Plan in 2018 (Energy Resources of Australia Ltd 2018) and the subsequent closure Feasibility Study (Energy Resources of Australia Ltd 2019) completed by the mine operator in early 2019, greater resolution on rehabilitation and closure activities is available. By aligning SSB assessment resources with the proposed rehabilitation schedule, risks associated with the regulatory approval process that may impact onsite closure by 2026 are reduced. SSB has been working with the mine operator and other stakeholders on initiatives to ensure the assessment and approval processes for rehabilitation activities are efficient and streamlined, while ensuring the environment remains protected. Scheduling by the mine operator in consultation with SSB and other stakeholders has identified when submission of proposals should occur to ensure there is sufficient time for the assessment process to be undertaken, including the provision of any additional information required.

Consultation between the mine operator and stakeholders on the contents of proposals generally commences well in advance of formal submission. This consultation includes discussion on the scope of potential environmental risks and the suitability of proposed controls. Depending on the type and complexity of the application, this consultation may range from agreement on the application content, through to weekly stakeholder meetings to track progression of critical elements of the application. For larger or more complex proposals, the mine operator is encouraged to submit supporting technical information and reports when completed, rather than lodging all material together. This allows stakeholders to commence assessment activities earlier than has traditionally occurred, identifying any critical deficiencies and allowing time for additional studies or investigations to be undertaken.

An assessment of key knowledge needs has been undertaken by SSB to inform the rehabilitation schedule and individual proposals. From this assessment, research projects have been refined to ensure the knowledge required to inform application assessments is available prior to the anticipated application submission dates (Welch et al. 2019). To augment SSB's internal assessment capability, a number of collaborative arrangements have been made with other institutions to undertake research to fill knowledge gaps.

Recognising that assessment of many of the rehabilitation proposals that will be submitted will involve highly specialised skill sets such as hydrogeology, surface water modelling, and geotechnical engineering, SSB has also developed long-term contractual relationships with specialised consultants. This allows the consultants to be involved in all stages of the assessment process from pre-assessment collaboration, through to implementation of any recommendations.

The development of relationships with the mine operator, other stakeholders, and collaborative relationships with external professionals ensures that SSB can undertake robust and thorough assessments and provide targeted advice on the environmental aspects associated with rehabilitation proposals.

\subsection{Stakeholder forums}

Stakeholder forums provide the opportunity for SSB, the mine operator, regulatory authorities, and other stakeholder groups to discuss all aspects of Ranger. The mine operator provides updates onsite activities and often presents information on new initiatives or planned activities. Information obtained from other supervisory activities such as inspections, audits, and environmental assessments are often discussed in detail at these forums and actions agreed should issues or concerns arise. 
Traditionally, the Ranger MTC focused primarily on environmental management and regulatory issues associated with the day-to-day operation of the mine. Information provided to this forum by the operator included environmental performance, outcomes of environmental incidents/investigations, and follow up on matters raised through routine submissions of environmental planning/reporting documentation. As operational activities onsite become more rehabilitation-focused, the MTC has become a valuable forum to discuss any rehabilitation risks identified through other supervisory activities such as audits and inspections.

To facilitate consultation on rehabilitation and closure-related activities, a closure consultative forum was initiated in 2018. At this forum, the mine operator reports to stakeholders on the progression and status of all rehabilitation and closure-related activities occurring onsite including those activities currently being planned or investigated as future rehabilitation options. This forum allows stakeholders to track the mine operator's rehabilitation activities progress and provides visibility on any emerging issues that may impact on closure timeframes or the achievement of rehabilitation objectives.

\section{$4 \quad$ Next steps}

A number of large-scale rehabilitation activities have commenced or will be commencing in the next few years. These rehabilitation activities offer new opportunities to further refine supervisory activities with a strong focus on collaborative engagement with the mine operator and other stakeholders. An example of this collaboration is the ongoing development of a monitoring program for the rehabilitation of Pit 1 as backfill is completed, the final landform developed, and ecosystem reestablishment commences. Through this collaborative involvement, SSB supervision activities can focus on the implementation of this agreed monitoring program, identify potential deviations from agreed strategies, and provide useful information to both the mine operator and the regulatory authorities on potential emerging issues that may impact on the success of the rehabilitation activity.

Recently, an ecosystem re-establishment working group has been established which includes representatives from SSB's research programs, the mine operator, traditional owners' groups, and other leading experts in the re-establishment of ecosystems on disturbed lands. This working group is a collaborative forum that will assist in developing and defining success criteria for all elements of ecosystem reestablishment at Ranger in consideration of the relevant Environmental Requirements.

Another area of focus for SSB supervision activities will be the ongoing refinement of consultation pathways to ensure stakeholder expectations are clearly defined, well in advance of commencement of a rehabilitation activity. This will ensure that these expectations can be incorporated into project management and scheduling by the mine operator. This will assist in ensuring that proposals submitted for assessment and approval contain no critical deficiencies that may delay the approval process.

\section{Conclusion}

The rehabilitation of Ranger continues to present exciting opportunities over a relatively short time frame for Supervising Scientist, the mine operator, and other stakeholders to work together to ensure the environment remains protected and Ranger is successfully rehabilitated and closed.

The recent initiatives and refinements in SSB's oversight activities presented in this case study are designed to ensure the regulatory system continues to assure the protection of the ARR as the mine transitions from operations to rehabilitation. Central to this transition is continuing engagement with the mine operator and other stakeholders including regulators and traditional owner representative groups. This engagement helps minimise the regulatory risks to rehabilitation timeframes and provides targeted assessment of rehabilitation activities occurring onsite while ensuring ongoing environmental protection.

The SSB looks forward to continuing to work with the mine operator and other stakeholders on the closure of Ranger. 


\section{References}

Commonwealth of Australia 1953, Atomic Energy Act 1953.

Commonwealth of Australia 1977, Ranger Uranium Environmental Inquiry, Second Report, Australian Government Publishing Service, Canberra, http://www.environment.gov.au/system/files/resources/b1ca8673-30dc-4693-925d-37ab42a0b8b5/files/rangeruranium-environmental-inquiry-fox-report-2.pdf

Commonwealth of Australia 1978, Environment Protection (Alligator Rivers Region) Act 1978.

Department of the Environment and Energy 1999, Environmental Requirements of the Commonwealth of Australia for the Operation of Ranger Uranium Mine, Commonwealth of Australia, Canberra, http://www.environment.gov.au/system/ files/resources/9cc1f5c4-18ad-4604-93bf-e9efd8390ee0/files/ranger-ers.pdf

Energy Resources of Australia Ltd 2018, Ranger Mine Closure Plan, http://www.energyres.com.au/sustainability/closureplan/

Energy Resources of Australia Ltd 2019, ASX Announcement: Ranger Project Area - Closure Feasibility Study Finalisation, http://clients3.weblink.com.au/pdf/ERA/02073794.pdf

Government of the Northern Territory 2001, Mining Management Act 2001

Welch, MA, Bartolo, RE \& Harford AJ 2019, 'A framework for identification and planning of environmental research needs to inform rehabilitation of Ranger uranium mine', in AB Fourie \& M Tibbett (eds), Proceedings of the $13^{\text {th }}$ International Conference on Mine Closure, Australian Centre for Geomechanics, Perth, pp. 525-534. 
